\title{
Medical pre-operative considerations for patients undergoing penile implantation
}

\author{
Thomas A. Masterson, Joseph Palmer, Justin Dubin, Ranjith Ramasamy \\ University of Miami Miller School of Medicine department of Urology, Miami, FL 33136, USA \\ Contributions: (I) Conception and design: TA Masterson, R Ramasamy; (II) Administrative support: R Ramasamy; (III) Provision of study materials or \\ patients: None; (IV) Collection and assembly of data: J Palmer, J Dubin, R Ramasamy; (V) Data analysis and interpretation: TA Masterson, J Palmer, \\ J Dubin, R Ramasamy; (VI) Manuscript writing: All authors; (VII) Final approval of manuscript: All authors. \\ Correspondence to: Thomas A. Masterson, MD. Department of Urology, University of Miami Miller School of Medicine, 1150 NW 14th St, Miami, \\ FL 33136, USA. Email: Thomas.masterson@jhsmiami.org
}

\begin{abstract}
Penile prosthesis surgery has become the standard treatment for patients with erectile dysfunction refractory to medical management. Refinements in the both the surgical technique and device manufacturing have made this a safe and reliable treatment with excellent patient satisfaction. In this review, we will overview the basic medical and pre-operative considerations for patients undergoing penile prosthesis implantation. We intend to provide a simple and practical checklist for the implanter to reference when considering implantation of a penile prosthesis.
\end{abstract}

Keywords: Penile prosthesis; pre-operative management; skin preparation; penile prosthesis in diabetics

Submitted Feb 15, 2017. Accepted for publication Mar 21, 2017.

doi: $10.21037 /$ tau.2017.03.85

View this article at: http://dx.doi.org/10.21037/tau.2017.03.85

\section{Introduction}

Penile implants have become relatively common in the treatment of erectile dysfunction. Although penile prosthetics date back to the 16th century, modern implants were first introduced in 1973 and 1974 when Dr. Scott and Drs. Small and Carrion described what are now referred to inflatable and semi rigid penile prosthesis respectively (1). Since then there have been significant design improvements, and today patients have the choice of semi rigid, 2-piece and 3 -piece penile prosthetics. In the modern era, it is estimated that approximately 25,000 penile prosthesis are implanted in North America annually (2). One of the most significant complications of penile prosthetic surgery is infection, and the implant surgeon must be aware of potential sources of infection. The goal of penile prosthetic surgery is to provide the patient with a functional erection for sexual intercourse while keeping morbidity low. In this review we will discuss important aspects of the medical history and provide a simple and practical checklist for the implanter to reference when considering implantation of a penile prosthesis.

\section{Medical history pertaining to penile implant surgery}

The past medical and past surgical histories are a crucial component of any patient encounter. Most patients seeking treatment for erectile dysfunction (ED) will have other medical comorbidities that can impact the success of prosthetic surgery. ED is often associated with vascular disease and diabetes mellitus, and prior medical evaluation is often warranted before surgical intervention is considered. We pay special attention to antiplatelet (AP) and anticoagulant (AC) use, previous abdominal and inguinal surgery, diabetic history, use of steroids and history of spinal cord injury.

\section{Antiplatelet and anticoagulant use and optimization}

Erectile dysfunction is more common in an elderly population and is often occurs in the presence comorbid of cardiovascular disease. A diagnosis of ED is often a marker of underlying coronary artery disease, even in younger patients, and places this population at a higher risk of future cardiovascular events including myocardial infarction and stroke $(3,4)$. We recommend medial consolation and 
Table 1 Summary of AP/AC recommendations from the AUA

\begin{tabular}{ll}
\hline Condition & Guideline \\
\hline Bare metal stents & Dual therapy for 1 month \\
Drug eluting stents & Dual therapy for 12 months \\
Atrial fibrillation requiring Warfarin & Consult cardiology, stop 5 days prior, restart in 12-24 hours \\
Mechanical valve & Cardiology consultation \\
\hline
\end{tabular}

Antiplatelet recommendations for penile prosthetics. Discontinuation of dual therapy. cardiology consultation, discontinue 10 days prior, restart within 7-10 days.

evaluation for cardiovascular disease if the patient has not already done so. As a result of comorbid disease, patients seeking surgical treatment may be taking therapeutic of prophylactic doses of AP or AC medications. The American Urologic Association classifies penile prosthetic surgery as high risk for bleeding, necessitating a careful medication review (5). Medical conditions requiring these classes of medication include congestive heart failure, coronary stents, atrial fibrillation, mechanical heart valves, and deep vein thrombosis or pulmonary embolus. Because prosthetic surgery is elective, many patients should wait until they are off anticoagulation before implantation. Dual Antiplatelet Therapy (DAPT) should be continued for at least 30 days after a bare metal stent, and for at least 12 months after a drug-eluting stent. In some cases, discontinuing or waiting to discontinue AP/AC is not possible. The AUA and EAU have developed guidelines to aid in patient selection $(6,7)$. Despite these guidelines, the risk of hemorrhage or thrombosis must be carefully weighed, and medical consultation should always be considered before discontinuation of AC/AP. In our institution we are comfortable operating on patients taking aspirin $81 \mathrm{mg}$. If the patient needs to be on clopidogrel or another anticoagulant we will place a drain close to the corpora cavernosa that exits out of inguinal area and remove 7 days after surgery (Table 1).

\section{Previous abdominal surgery}

Prior abdominal surgery can be predictive of intraoperative difficulty, specifically in regard to reservoir placement. Open radical prostatectomy had the advantage of keeping the space of Retzius intact. Robotic assisted laparoscopic prostatectomy (RALP) has become the surgical treatment of choice for prostate cancer, but has made reservoir placement more challenging because the space of Retzius can be compromised. When interviewing patients we pay particular attention to a history of RALP, radical cystectomy, and inguinal hernia repair. In these situations, we choose to place the reservoir in a submuscular location (8). Recent review of submuscular, below the internal oblique but above the transversalis fascia, reservoir placement have proven this technique to be a safe and effective alternative with high patient satisfaction $(9,10)$. Inguinal surgeries, such as prior hernia repair with mesh, can also make traditional reservoir placement more complicated, and when possible we choose to place the reservoir on the side opposite the hernia repair. In cases of bilateral inguinal hernia repair we will consider submuscular placement of the reservoir. Men need to be warned about the possibility of a palpable reservoir and the rare possibility of herniation of the reservoir.

\section{DM and HbA1c optimization, steroid use and spinal cord injury patients}

Classically diabetics have been considered a high risk patient group for complications related to infection (11-13). Reasonable evidence suggested that poorly controlled diabetes with $\mathrm{Hbg}$ A1c greater than 11.5, posed significant risk to infection and future explanation $(11,12,14)$. More contemporary meta-analysis data has changed opinion, showing similar rates of infection between diabetics, poorly controlled diabetics and non-diabetics (15) (Table 2). Despite this, we still ask that pts with hemoglobin A1c greater than 10 to optimize their diabetic control prior implantation.

Unfortunately, unlike diabetics, there continues to be strong evidence suggesting that chronic steroid use and spinal cord injury increase patient's infection risk. Whenever possible, we prefer to delay surgery until patients have discontinued steroid use (19). For spinal cord injury patients, we counsel them on the additional infection risk because of urine stasis and complications from neurogenic bladder requiring intermittent catheterizations $(15,19)$. 
Table 2 Summary of modern studies comparing the rate of penile prosthetic infection in diabetic (DM) and non-diabetic patients

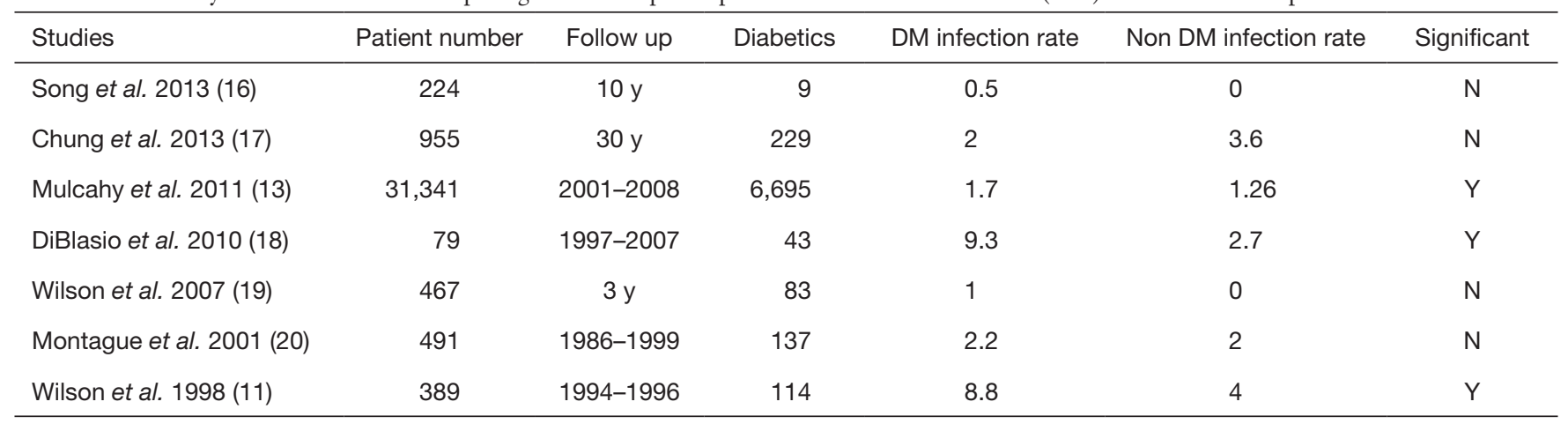

Diabetics and prosthetic infections.

\section{Preoperative considerations}

\section{Preoperative prophylactic antibiotics}

Even though penile implants generally have a low morbidity, the most devastating complication is infection. The majority of perioperative considerations focus on decreasing the incidence of infection. Overall, infections affect around $3 \%$ of penile implants during the first year after surgery, with this rate being increased for revision surgeries $(20,21)$. In attempts to minimize post-operative infection, prophylactic antibiotics have been studied and shown to be efficacious. While there have been no studies specifically investigating home oral antibacterial prophylaxis for penile implants, there have been extensive studies on orthopedic implants and hernia mesh surgeries $(22,23)$. Multiple studies of penile implantation mention the use of preoperative prophylactic antibiotic, but are not directly investigated (24). We recommend prophylactic preoperative antibiotics (2 days of Bactrim or Ciprofloxacin) for all patients undergoing penile implant surgery.

\section{Urinalysis and urine culture}

At our institution we obtain preoperative urine cultures because we routinely place Foley catheters prior to surgery for the purpose of identification of the urethra intra operatively, decompression of the bladder, and to allow for 24 hours of bedrest post operatively. The use of a preoperative urinalysis and culture is theoretically useful to identify a potential source for bacteremia, and thus a potential prosthesis infection (25). Despite this, studies of orthopedic procedures, treating positive urinalysis and culture made no difference in infection rates (26-28). There are no studies to show a reduction in prosthetic infections when treating asymptomatic bacteruria. Cultures of infected prosthesis show skin flora, like Staphylococcus epidermidis, are the most common organisms $(25,26)$. Despite there being a lack of evidence, approximately $50-60 \%$ of implanters still routinely obtain preoperative urine cultures (29).

\section{Preoperative scrotal wash with Chlorhexidine wash}

There is no data specifically investigating the use of washes prior to penile prosthetic implantation as a means to reduce infection. There is evidence from orthopedic surgery literature so suggest a reduction in surgical site infection when patient used chlorhexidine impregnated washes at home the day prior to surgery (30) We recommend Hibiclens (4\% w/v chlorhexidine gluconate) skin wash to use starting 2 days prior to surgery.

\section{Hair removal}

Hair removal technique in penile prosthetic surgery is believed to be a potential risk for infection from skin flora, despite any robust evidence. We ask that out patients not to shave, or clip themselves before surgery. General surgery literature suggests clippers are the preferable method of hair removal in the preoperative setting. However because of the delicate, irregular, and elastic skin of the male genitalia urologists have preferred razors for hair removal. Grober et al. compared 215 patients undergoing genital surgery to either razor (108 patients) or clipper (107 patients) perioperative hair removal without showing a difference in surgical site infection (two in razor $v s$. two in clipper) (31). In the absence of any evidence to the contrary, the Sexual Medicine Society of North America recommends that surgeons be permitted their choice of razors or clippers for 
Table 3 Summary of studies comparing preoperative chlorhexidine and iodine based skin preparation

\begin{tabular}{lllll}
\hline Study & Surgery type & Time frame & Patient number & Outcome measure \\
\hline Darouiche et al. 2010 (36) & Clean contaminated & 30 days & Chlorhexidine 409 & $9.5 \%$ infection rate \\
& & & lodine 440 & $16.1 \%$ infection rate \\
Yeung et al. 2013 (37) & Penile prosthetics & Mean 9.75 months & Chlorhexidine 50 & $8 \%$ positive skin cultures \\
& & & lodine 50 & $32 \%$ positive skin cultures \\
\hline
\end{tabular}

Chlorhexidine vs. iodine

preoperative preparation of the male genitalia (32).

\section{Operative considerations}

\section{Intraoperative antibiotics}

As with all open surgical procedures, antibiotics at the time of incision are mandatory. Advances in penile prosthetics have included proprietary antibiotic and hydrophilic coatings that have reduced overall infection rates, however preoperative antibiotics are still recommended $(33,34)$. The AUA currently recommends perioperative use of an aminoglycoside (or aztreonam) and a first or second generation cephalosporin or vancomycin, which might be continued up to $24 \mathrm{~h}$ after surgery (33). Acceptable alternative antibiotics include ampicillin/sulbactam, ticarcillin/clavulanate, and piperacillin/tazobactam for less than 24 hours if no previous bacterial colonization. Survey data among implanters shows significant variety of first choice preoperative antibiotics (35). When there is no contraindication we use Vancomycin $1 \mathrm{~g}$ and Gentamicin $160 \mathrm{mg}$ IV. The vancomycin is started in the preoperative area as infusion takes 60 minutes to complete while the gentamicin is infused during time out. We continue both medications for $24 \mathrm{~h}$ post operatively.

\section{Skin preparation}

Careful skin preparation is critical for successful implantation and prevention of contamination from skin flora. It is believed that the primary route of implant infections occur before or during the implantation, and elimination of skin flora through proper skin antisepsis will reduce implant infection rates (34)

Historically, povidone-iodine has been the prep of choice while chlorhexidine-alcohol scrubs were not utilized due lack of evidence of superiority, and concerns of urethral irritation. Nevertheless, recent evidence now suggests chlorhexidine to be the superior scrub. Darouiche et al. showed that the overall rate of surgical site infection was significantly lower in the chlorhexidine-alcohol group than the povidone-iodine group (36) This was again later confirmed by Yeung et al. (37). In addition to concluding that chlorhexidine was a superior scrub compared to iodine in the eradication of skin flora of the surgical site, they noted that there was no urethral complications or genital complications associated with either prep peri-operatively or postoperatively (38). With lower infection rate incidence and no significant irritation of the genitalia, we prefer to use a chlorhexidine based prep (Table 3).

\section{No touch technique}

Even with careful skin antisepsis, pre-and post-operative antibiotic regimens, irrigation of the surgical field with antimicrobial solution, and the use of antibiotic coated devices, prosthetic infections occur at unacceptably high rates. With room for improvement, a goal became to find new ways to reduce skin flora contamination. In 2011, Eid presented the "no-touch" technique for IPP surgery. The technique builds off of the traditional approach through the penoscrotal raphe until the level of Buck's fascia is reached. To reduce skin contamination, all surgical instruments and gloves that have been used until this point are considered unclean and removed from the field. New, unused instruments and gloves are then utilized to cover the surgical field with a clear drape. Above the original incision site, the surgeon creates a small opening in the drape and then performs the remainder of the implant procedure through the drape. This allows the surgeon to avoid contact with the original surgical site. The focus of this technique is to avoid all contact with the patient's skin, the surgeon's hands, the surgical instruments, and the implant, reducing the risk of contamination and infection $(24,39)$. A single surgeon study showed that performing the no-touch technique with antibiotic coated penile prosthesis reduced his infection rate to $0.44 \%$ from a previous rate of $1.67 \%$ 


\section{Checklist for penile implant surgery}

\section{Preoperative \\ $\square$ Cardiology/Medical Clearance \\ $\square$ Urine Culture \\ $\square \mathrm{HbgA1c}<10$ \\ $\square$ Stop antiplatelet 7 days prior}

2 Days prior to surgery
$\square$ Oral Antibiotics
$\square$ Hibiclens scrub twice a day
Day of surgery
$\square$ Wash with soap and water
$\square$ Perioperative antibiotics:Vancomycin and Gentamycin
$\square$ Hair removal: clippers or razors
$\square$ Chlorhexidine scrub prep

Figure 1 Proposed checklist for penile implantation.

when compared to the standard technique $(\mathrm{P}=0.0042)$ (39). There are downsides that include increasing operating time by 10 minutes as well as the additional cost incurred due to the requirement of additional instruments and supplies (39) The procedure is rather new and there is limited data on the technique's efficacy in reducing infection rates, and whether it is worth the additional costs to perform.

\section{Conclusions}

Penile prosthesis impanation is an effective treatment for erectile dysfunction. A thorough medical and surgical history is a critical part of the preoperative workup. There are established guidelines for the management of antiplatelet and anticoagulation. Much of what we understand about prevention of prosthetic infections is extrapolated from orthopedic and general surgery literature leading to significant heterogeneity among surgical preparation and techniques. Randomized clinical trials comparing preoperative antibiotics do not exist and are unlikely to be undertaken. After reviewing the literature and our own practice, we propose a simple preoperative checklist that may be utilized by the implant surgeon. Figure 1. We recommend using a consistent preoperative preparation that the surgeon is comfortable with when approaching penile implant surgery.

\section{Acknowledgements}

None.

\section{Footnote}

Conflicts of Interest: The authors have no conflicts of interest to declare.

\section{References}

1. Le B, Burnett AL. Evolution of penile prosthetic devices. Korean J Urol 2015;56:179-86.

2. Darouiche RO, Bella AJ, Boone TB, et al. North American consensus document on infection of penile prostheses. Urology 2013;82:937-42.

3. Jackson G, Boon N, Eardley I, et al. Erectile dysfunction and coronary artery disease prediction: evidence-based guidance and consensus. Int J Clin Pract 2010;64:848-57.

4. Hackett G, Krychman M, Baldwin D, et al. Coronary Heart Disease, Diabetes, and Sexuality in Men. J Sex Med 2016;13:887-904.

5. Gupta AD, Streiff M, Resar J, et al. Coronary stent management in elective genitourinary surgery. BJU Int 2012;110:480-4.

6. Culkin DJ, Exaire EJ, Green D, et al. Anticoagulation and antiplatelet therapy in urological practice: ICUD/AUA review paper. J Urol 2014;192:1026-34.

7. Douketis JD, Spyropoulos AC, Spencer FA, et al. Perioperative management of antithrombotic therapy: Antithrombotic Therapy and Prevention of Thrombosis, 9th ed: American College of Chest Physicians Evidence-Based Clinical Practice Guidelines. Chest 2012;141:e326S-50S.

8. Hakky TS, Kohn TP, Ramasamy R. Submuscular Abdominal Wall Placement of IPP Reservoir. J Sex Med 2016;13:1573-7.

9. Karpman E, Brant WO, Kansas B, et al. Reservoir alternate surgical implantation technique: preliminary outcomes of initial PROPPER study of low profile or spherical reservoir implantation in submuscular location or traditional prevesical space. J Urol 2015;193:239-44.

10. Stember DS, Garber BB, Perito PE. Outcomes of abdominal wall reservoir placement in inflatable penile prosthesis implantation: a safe and efficacious alternative to the space of Retzius. J Sex Med 2014;11:605-12.

11. Wilson SK, Carson CC, Cleves MA, et al. Quantifying risk of penile prosthesis infection with elevated glycosylated hemoglobin. J Urol 1998;159:1537-9; discussion 1539-40.

12. Bishop JR, Moul JW, Sihelnik SA, et al. Use of glycosylated hemoglobin to identify diabetics at high risk for penile 
periprosthetic infections. J Urol 1992;147:386-8.

13. Mulcahy JJ, Carson CC 3rd. Long-term infection rates in diabetic patients implanted with antibiotic-impregnated versus nonimpregnated inflatable penile prostheses: 7-year outcomes. Eur Urol 2011;60:167-72.

14. Cakan M, Demirel F, Karabacak O, et al. Risk factors for penile prosthetic infection. Int Urol Nephrol 2003;35:209-13.

15. Christodoulidou M, Pearce I. Infection of Penile Prostheses in Patients with Diabetes Mellitus. Surg Infect (Larchmt) 2016;17:2-8.

16. Song WD, Yuan YM, Cui WS, et al. Penile prosthesis implantation in Chinese patients with severe erectile dysfunction: 10-year experience. Asian J Androl 2013;15:658-61.

17. Chung E, Van CT, Wilson I, et al. Penile prosthesis implantation for the treatment for male erectile dysfunction: clinical outcomes and lessons learnt after 955 procedures. World J Urol 2013;31:591-5.

18. DiBlasio CJ, Kurta JM, Botta S, et al. Peyronie's disease compromises the durability and component-malfunction rates in patients implanted with an inflatable penile prosthesis. BJU Int 2010;106:691-4.

19. Wilson SK, Delk JR 2nd. Inflatable penile implant infection: predisposing factors and treatment suggestions. J Urol 1995;153:659-61.

20. Montague DK, Angermeier KW, Lakin MM. Penile prosthesis infections. Int J Impot Res 2001;13:326-8.

21. Wilson SK, Zumbe J, Henry GD, et al. Infection reduction using antibiotic-coated inflatable penile prosthesis. Urology 2007;70:337-40.

22. Sanabria A, Domínguez LC, Valdivieso E, et al. Prophylactic antibiotics for mesh inguinal hernioplasty: a meta-analysis. Ann Surg 2007;245:392-6.

23. Southwell-Keely JP, Russo RR, March L, et al. Antibiotic prophylaxis in hip fracture surgery: a metaanalysis. Clin Orthop Relat Res 2004;(419):179-84.

24. Eid JF. No-touch technique. J Sex Med 2011;8:5-8.

25. Koulouvaris P, Sculco P, Finerty E, et al. Relationship between perioperative urinary tract infection and deep infection after joint arthroplasty. Clin Orthop Relat Res 2009;467:1859-67.

26. Lawrence VA, Kroenke K. The unproven utility of preoperative urinalysis. Clinical use. Arch Intern Med 1988;148:1370-3.

27. Martínez-Vélez D, González-Fernández E, Esteban J, et al. Prevalence of asymptomatic bacteriuria in knee arthroplasty patients and subsequent risk of prosthesis infection. Eur J Orthop Surg Traumatol 2016;26:209-14.

28. Rusk MH. Avoiding Unnecessary Preoperative Testing. Med Clin North Am 2016;100:1003-8.

29. Katz DJ, Stember DS, Nelson CJ, et al. Perioperative prevention of penile prosthesis infection: practice patterns among surgeons of SMSNA and ISSM. J Sex Med 2012;9:1705-12; quiz 712-4.

30. Zywiel MG, Daley JA, Delanois RE, et al. Advance pre-operative chlorhexidine reduces the incidence of surgical site infections in knee arthroplasty. Int Orthop 2011;35:1001-6.

31. Grober ED, Domes T, Fanipour M, et al. Preoperative hair removal on the male genitalia: clippers vs. razors. J Sex Med 2013;10:589-94.

32. Sexual Medicine Society of North America; Position statements: Razors and Peroperative Preparation of the Male Genitalia. Available online: http://www.smsna.org/ V1/about/position-statements

33. Wolf JS Jr, Bennett CJ, Dmochowski RR, et al. Best practice policy statement on urologic surgery antimicrobial prophylaxis. J Urol 2008;179:1379-90.

34. Wilson SK, Costerton JW. et al. Biofilm and penile prosthesis infections in the era of coated implants: a review. J Sex Med 2012;9:44-53.

35. Wosnitzer MS, Greenfield JM. Antibiotic patterns with inflatable penile prosthesis insertion. J Sex Med 2011;8:1521-8.

36. Darouiche RO, Wall MJ Jr, Itani KM, et al. ChlorhexidineAlcohol versus Povidone-Iodine for Surgical-Site Antisepsis. N Engl J Med 2010;362:18-26.

37. Yeung LL, Grewal S, Bullock A, et al. A comparison of chlorhexidine-alcohol versus povidone-iodine for eliminating skin flora before genitourinary prosthetic surgery: a randomized controlled trial. J Urol 2013;189:136-40.

38. Henry GD, Wilson SK, Delk JR 2nd, et al. Penile prosthesis cultures during revision surgery: a multicenter study. J Urol 2004;172:153-6.

39. Eid JF. Penile Implant: Review of a "No-Touch" Technique. Sex Med Rev 2016;4:294-300.

Cite this article as: Masterson TA, Palmer J, Dubin J, Ramasamy R. Medical pre-operative considerations for patients undergoing penile implantation. Transl Androl Urol 2017;6(Suppl 5):S824-S829. doi: 10.21037/tau.2017.03.85 